\title{
The learning of an optional extradimensional/reversal shift problem by rats'
}

\author{
N. S. SUTHERLAND, SUSSEX UNIVERSITY \\ N. J. MACKINTOSH, OXFORD UNIVERSITY
}

Rats were trained in three stages to perform visual discriminations on a Lashley jumping stand. At Stage I they were trained with one cue (RS) relevant, and a second cue (EDS) present but irrelevant. At Stage II they were trained with both cues relevant but with the value of the RS cue reversed. At Stage III Ss were given transfer test with each cue presented on its own. The Stage III results showed that rats had learned much more about the EDS cue at Stage II than about the RS cue. Rats overtrained at Stage I did not learn more about the RScue than rats trained only to criterion.

Mackintosh (1965) and Sutherland (1964) have suggested that the overtraining reversal effect (ORE) in rats can be explained in terms of a two-stage model of discrimination learning. If it is assumed that the main effect of overtraining is to strengthen attention to the relevant dimension (the relevant analyzer) rather than to strengthen response attachments, then overtraining should decrease the extent to which the relevant analyzer is extinguished during reversal, and overtrained Ss will reverse more rapidly than non-overtrained Ss.

One prediction derivable from such a hypothesis is that if rats are trained at Stage I on a problem with one cue relevant and another irrelevant, and are then shifted at Stage II to a problem soluble either as a reversal of the original discrimination (RS), or in terms of the previously irrelevant cue (an extradimensional shift, EDS), then Ss overtrained at Stage I will learn more about the Stage II RS cue than non-overtrained Ss. (This is not the same as predicting that overtrained Ss will learn more about the RS cue at Stage II than about the EDS cue; such a prediction can only be made from a two-stage model after further parameters have been specified.)

While this optional shift design has been frequently used with human Ss, there are only two such experiments using rats. Kendler, Kendler, \& Silfen (1964) found that rats trained only to criterion at Stage I learned very little about the RS cue at Stage II. Tighe \& Tighe (in press) found that overtraining at Stage I did not increase the amount learned about the reversal cue at Stage II, thus contradicting our prediction. Since their experimental situation is one in which rats do not even show an ORE (Tighe, Brown, \& Youngs, 1965), their results on optional shifts do not necessarily conflict with our own explanation of the ORE. Our own experiment was conducted on a Lashley jumping stand on which it is known that an ORE is obtained (Mackintosh, $1962,1963)$. In both the study by Kendler et al and that by Tighe and Tighe, the test for RS and EDS learning was provided by opposing the two cues after Ss had learned Stage II. In both studies, most Ss showed no consistent pattern of responding on the opposition tests. In order to obtain a clearer indication of how much each $S$ had learned about each cue, we gave transfer tests to each cue separately after Stage II. Finally, since it has been suggested that magnitude of reward is an important factor in producing the ORE (Theios \& Blosser, 1965), two different reward magnitudes were used in the present experiment.

\section{Subjects}

\section{METHOD}

The Ss were 40 male 100-day-old hooded rats from the colony at the Oxford University Institute of Experimental Psychology.

\section{Apparatus and Procedure}

The Ss were given simultaneous discrimination training on a modified Lashley jumping stand as described by Mackintosh (1962). All Ss were first pretrained to jump to blank doors. Ten trials a day were given and a non-correction procedure was used throughout. Eight different shapes were used-black, white and grey horizontal and vertical rectangles measuring $10 \times 2.5$ $\mathrm{cm}$ and black and white $5 \times 5 \mathrm{~cm}$ squares. The shapes were cut from $1 / 4$ in. Perspex and were mounted centrally on the brown hardboard doors in the jumping stand.

\section{Experimental Design}

The experiment was run in three stages.

Stage I. Half the Ss (Group Or.) were trained to discriminate between a vertical and horizontal rectangle with vertical positive. Two pairs of shapes were useda black vertical rectangle presented with a white horizontal and a white vertical rectangle presented with a black horizontal. A brightness cue was therefore always present but was irrelevant. The same pairs of shapes were used with the remaining animals (Group $\mathrm{Br}$.) but the white rectangle was always positive irrespective of whether it was horizontal or vertical. Within each group half the Ss (Group T) were trained to a criterion of 18 out of 20 successive jumps correct with the last 10 jumps all correct; the remaining Ss (Group OT) were trained to the same criterion and then given 100 overtraining trials. Within each of the four subgroups thus formed, half the Ss (Group 5') received 5 sec. feeding after a correct jump, half (Group 20") received 20 sec. feeding.

Stage II. All Ss were trained to discriminate between a black horizontal rectangle and a white rectangle with black horizontal positive. Both the orientation and 
brightness cue were therefore relevant, and the value of the cue learned at the first stage was reversed for all Ss. All Ss were trained to a criterion of 18 out of 20 successive jumps correct.

Stage III. All Ss were next given transfer tests mixed with retraining trials on the Stage II discrimination. Every third trial was a retraining trial. The Ss received 20 transfer tests with a black and white square (brightness tests) and 20 with grey horizontal and vertical rectangles (orientation tests). In transfer tests Ss received reward whichever shape they selected.

\section{Stage I}

\section{RESULTS}

The number of trials taken to reach criterion by the main groups was as follows: Group $T$ 126, Group OT 126; Group Or. 127, Group Br. 125; Group 5" 130, Group 20" 122. Neither the discrimination Ss were taught nor the amount of reward given significantly affected performance.

\section{Stage II}

The number of trials taken to reach criterion for the main groups was as follows: Group $T$ 180, Group OT 160; Group Or. 159, Group Br. 182; Group 5' 161, Group 20"180. Once again no effect was significant.

One puzzling result at Stage II was that Group OT did not take longer to cease responding to their original positive than Group T. Group T averaged 14.9 consecutive responses to their original positive before the first trial on which they selected the original negative stimulus; the comparable figure for Group OT was 9.4. Group $T$ averaged 4.15 days responding above chance to their original positive, Group OT only 3.15 days. The differences between the two groups' scores were just short of significance.

\section{Stage III}

The main results are shown in Table 1 . It will be seen thatGroup OT did not learn more about the reversal cue than Group T. The scatter of transfer results was very much greater on the reversal cue than on the EDS cue ranging from two out of 20 correct to 20 out of 20, whereas no $S$ scored less than 15 correct on the

Results of Transfer Tests

\begin{tabular}{lcc} 
Cue & Group T & Group OT \\
\hline RS & 11.3 & 11.1 \\
EDS & 17.3 & 18.8 \\
\hline
\end{tabular}

The figures represent the mean number of responses in 20 tests to the stimulus whose value was positive at Stage II.
EDS cue. An analysis of variance was performed on the transfer test results; the difference in performance on the RS cue and the EDS cue was highly significant $(p<.001)$. The difference was not due solely to the difference in the variances of the two groups' scores, since a non-parametric test (Wilcoxson's method for unpaired replicates) yielded the same level of significance.

\section{DISCUSSION}

The results obtained do not agree with the prediction made from our two-process model of discrimination learning. Overtrained Ss did not learn more about the RS cue at Stage II than did non-overtrained Ss. Failure to obtain the predicted result may be connected with the fact that overtrained Ss tended to extinguish their responses to the original positive stimulus faster than non-overtrained. In two previous experiments, Mackintosh $(1962,1963)$ found that during reversal overtrained Ss took significantly longer than non-overtrained to extinguish their responses to the Stage I positive stimulus. Moreover, Mackintosh (1962) also found that when separate groups are shifted one to an RS problem, the other to an EDS problem, overtraining assists RS and retards EDS. We are unable satisfactorily to account for the discrepancies between the present results and the previous ones. The results suggest that when rats are given the option of solving a problem in terms of an RS shift or an EDS shift, they learn predominantly in terms of the EDS shift.

\section{References}

Kendler, T. S., Kendler, H. H., \& Silfen, C. K. Optional shift behavior of albino rats. Psychon. Sci., 1964, 1, 5-6.

Mackintosh, N. J. The effects of overtraining on a reversal and a nonreversal shift. J. comp. physiol. Psychol., 1962, 55, 555-559.

Mackintoshr, N. J. The effect of irrelevant cues on reversal learning in the rat. Brit. J. Psychol., 1963, 54, 127-134.

Mackintosh, N. J. Selective attention in animal discrimination learning. Psychol. Bull., 1965, 64, 124-150.

Sutherland, N. S. The learning of discrimination by animals. Endeavour, $1964,23,148-152$.

Tighe, T. J., \& Tighe, L. S. Overtraining and optional shift behavior in rats and children. $J$ : comp. physiol. Psychol., in press.

Tighe, T. J., Brown, P. L., \& Youngs, E. A. The effect of overtraining on the shift behavior of albino rats. Psychon. Sci., $1965,2,141-2$.

Theios, J., \& Blosser, D. The overlearning reversal effect and magnitude of reward. J. comp. physiol. Psychol., 1965, 59, 252-7.

\section{Note}

1. This research was part of a project on Stimulus Analysing Mechanisms supported by the American Office of Naval Research (Contract N62558-4286). 